\title{
A CONTRIBUIÇÃO DO CURRICULO DE LÍNGUA PORTUGUESA PARA O DESENVOLVIMENTO DA AUTONOMIA DO ALUNO DA REDE ESTADUAL DE ENSINO
}

\author{
Sandra Elias Takaki ${ }^{1}$, Carmen Lúcia Dias ${ }^{2}$, Helena Faria de Barros ${ }^{2}$ \\ ${ }^{1}$ Discente do mestrado em Educação - UNOESTE. ${ }^{2}$ Docente do mestrado em Educação - UNOESTE. E-mail: \\ sandtakaki@yahoo.com.br
}

\section{RESUMO}

O presente artigo tem por objetivo refletir sobre a contribuição do Curriculo de Língua Portuguesa, por meio do material didático desenvolvido nas escolas estaduais paulistas, com alunos do Ensino Médio, para o desenvolvimento da autonomia nos alunos. A partir da leitura de pesquisadores da área, os resultados demonstram que as condições de ensino-aprendizagem refletem as imagens e os significados sobre o Projeto de Vida, como também, o desenvolvimento da autonomia. Indicam também que existe uma enorme lacuna entre as políticas públicas socioeducacionais destinadas para os adolescentes, e as possibilidades de desenvolvimento de habilidades para realizarem seus projetos de vida, uma vez que estas políticas representam um caminho de oportunidades, sobretudo, para aqueles adolescentes que se constituem a maioria, que dependem exclusivamente destas políticas para desenvolver habilidades de vida e acadêmicas para a realização de seu projeto de vida com autonomia.

Palavras-chave: Autonomia, Currículo de Língua Portuguesa, Alunos do Ensino Médio, Políticas Públicas e Projeto de vida.

\section{INTRODUÇÃO}

[...] autonomia não é mais uma liberdade absoluta, emancipada de qualquer dependência, mas uma autonomia que depende de seu meio ambiente seja ele biológico, cultural ou social. Assim, um ser vive para salvaguardar sua autonomia, trabalha, despende energia, e deve, obviamente, abastecer-se de energia em seu meio, do qual depende. (MORIN, 2010, p.35).

O modelo tradicional de ensino tratava o conhecimento como um conjunto de informações que eram transmitidas pelos professores aos estudantes. Nessa abordagem, os aprendizes assumiam o papel de ouvintes, cuja função maior era a de memorização. Mesmo considerando uma possível interação existente no silêncio dos estudantes, o professor não diagnosticava as dificuldades de aprendizagem apresentadas pelos alunos. O professor era visto como o detentor do saber, o responsável pela aprendizagem do aluno, somente ele era capaz de ensinar crianças e jovens.

Ensinar, no modelo tradicional (DIAS; MONDIN; MACÊDO, 2012), era transmitir conhecimentos, fazer com que a nova geração seja capaz de reproduzir o que lhe foi ensinado. Os 
alunos não participavam das aulas, apenas ouviam e tinham que memorizar o conteúdo transmitido pelo professor; conteúdo esse que não era voltado para as necessidades dos alunos, mas para a sistematização necessária para a formação de pessoas disciplinadas, obedientes, capazes de se adaptarem à sociedade na qual estavam inseridos. A escola era vista como uma instituição única, com os mesmos sentidos e objetivos, tendo como função garantir a todos o acesso ao conjunto de conhecimentos socialmente acumulados pela sociedade. Tais conhecimentos, portanto, são reduzidos a produtos, resultados e conclusões, sem levar em conta o valor determinante dos processos. Ensinar se torna transmitir esse conhecimento acumulado e aprender se torna assimilá-los. Nessa lógica, não faz sentido estabelecer relações entre o vivenciado pelos alunos e o conhecimento escolar e o extra-escolar, justificando-se a desarticulação existente entre o conhecimento escolar e a vida dos alunos. A prática escolar desconsidera a totalidade das dimensões humanas dos sujeitos - aluno, professores e funcionários, que dela participam.

Precisa-se conceber uma educação voltada para o ser humano e seus processos formativos visto que não dá mais para educar os jovens dentro desse contexto. No entanto, hoje, graças principalmente às tecnologias de informação e comunicação, o acesso ao conhecimento está mais diversificado. O papel da escola e do professor com certeza não é mais o mesmo. O conhecimento está disponível em todos os lugares (livros, revistas especializadas, jornais e internet). O professor, diante disso, não representa o recurso de mais fácil acesso.

Percebe-se atualmente que a sociedade, as pessoas e os alunos mudaram, o contexto sócio-histórico é outro. O conhecimento fragmentado, estático, fixo, definido e previsível deu lugar a um conhecimento inacabado, que está em constante construção, parte de uma rede. Não há mais conhecimento isolado, mas um o conhecimento dinâmico, interligado e contextualizado. É necessário entender o ensinar e o aprender nessa nova sociedade que estamos vivendo. Não havendo mais separação do conhecimento, e considerando os saberes de todos os indivíduos, há de se considerar o diálogo como forma de aprendizagem, o ouvir, e toda a relação com os meios externos à escola. Não estamos dizendo para se comparar a profundidade do saber do docente com o saber dos alunos, mas, considerar que todo aluno tem uma história de vida, uma bagagem cognitiva, afetiva e de experiências singulares, e que isso pode e precisa ser usado em prol do processo de aprendizagem para auxiliar no desenvolvimento da autonomia dos alunos, uma vez que consideramos que o desenvolvimento da autonomia é uma parte importante do processo de ensino-aprendizagem. Assim, vemos que à escola cabe muito mais do que a transmissão de 
saberes. É necessário um trabalho que se volte para o desenvolvimento da autonomia dos estudantes, que estimule a reflexão, o diálogo e as ações pautadas em princípios de democracia e justiça. Para tanto, o trabalho da escola deve-se articular às vivências dos estudantes, levando em conta seus contextos, suas experiências, seus conflitos e inquietações.

Portanto, um dos primeiros objetivos da Educação é a formação humana, que diz respeito a uma prática escolar que constitui um elemento essencial na formação dos alunos como cidadãos capazes de exercerem seus direitos e deveres de forma plena com autonomia, no sentido de interagir com diversas situações, havendo assim, um desenvolvimento na convivência social e cultural. E, no caso do currículo de Língua Portuguesa, que seja voltado não apenas para a informação "armazenamento de conhecimento", mas, para a formação global do aluno, sua formação humana como indivíduo e como cidadão.

Observa-se que o vínculo da educação e da formação humana com emancipação e autonomia, implica, portanto, processos globais de formação do ser humano, cujos objetivos e características ultrapassam a ideia estrita de ensino como sistematização de conhecimentos e transmissão de conteúdos escolares. Essa formação humana pretende ser, portanto, uma prática social que considera a integração da educação, das escolas, dos serviços de saúde, das organizações de trabalho e da comunidade em geral. Se a escola deve atender a todos e pensar na formação do cidadão pressupõe introduzir novas temáticas curriculares, coerentes com os anseios e as necessidades da maioria da população. Assim, a escola deve trabalhar, além dos conhecimentos científicos e culturais tradicionais, conteúdos contextualizados na vida comunitária e cotidiana das pessoas, em suas realções locais e concretas. Em outras palavras: a escola deve incorporar, também, a cultura popular e promover uma aproximação entre os saberes da realidade vivenciada pelos alunos em seu dia-a-dia e aos conhecimentoscientíficos e outras realidades culturaais, como forma de enriquecimento da própria experiência.

Diante desse contexto percebe-se que o atual currículo aponta para uma nova perspectiva no ensino da língua portuguesa, enxergada na formação docente constante, no aprofundamento das questões que afetam a inclusão social, no aproveitamento das teorias humanistas e cognitivistas, na descoberta de novas metodologias de ensino e na superação da barreira entre o que se ensina e o que realmente se aprende.

Portanto, o professor de Língua Portuguesa, por meio do despertar de sua curiosidade epistemológica e de sua vocação como mediador no processo de ensino e aprendizagem, deve preparar-se para ser o condutor do educando na busca pela sua autonomia, na compreensão e no 
uso de uma linguagem útil e necessária, tornando-o sujeito independente, capaz de realizar-se satisfatoriamente em suas relações pessoais e profissionais.

Vale destacar que o presente artigo pretende refletir sobre a contribuição, a partir do material do Currículo de Língua Portuguesa da Secretaria da Educação do Estado de São Paulo (SÃO PAULO, 2018; 2010) como estimulo ao desenvolvimento da autonomia dos alunos - seus textos, suas discussões e as reflexões que o material propõe - quando trabalhado por um profissional consciente.

A educação que se propõe é a que tem como prioridade o desenvolvimento pleno das crianças, respeitando os interesses dos alunos, estimulando a pesquisa e a criatividade. Neste sentido Piaget (1998, p.67) defende: uma "educação do pensamento, da razão e da própria lógica, é necessário e é condição primeira da educação da liberdade. Não é suficiente preencher a memória de conhecimentos úteis para se fazer homens livres: é preciso formar inteligências ativas".

Não há desenvolvimento da autonomia num ambiente onde prevalece o autoritarismo do professor, em que os alunos vêem o professor como dono exclusivo do saber. Se esta afirmativa se faz verdade, a simples transmissão do saber será a prática na sala de aula. Acredita-se que através de uma relação de respeito mútuo entre professor-aluno, a cooperação entre iguais e respeitando o aluno como sujeito construtor do seu conhecimento, poderá contribuir para a formação de indivíduos autônomos.

\section{A Autonomia}

De acordo com Piaget (1975, p.48) “a autonomia não está relacionada com isolamento, mas à capacidade de aprender sozinho e respeito ao ritmo próprio". Na verdade, entende Piaget (1973), que o florescer do pensamento autônomo e lógico operatório é paralelo ao surgimento da capacidade de estabelecer relações cooperativas. Quando os agrupamentos operatórios surgem com as articulações das intuições, a criança torna-se cada vez mais apta a agir cooperativamente.

Segundo Piaget (1973) ser autônomo significa estar apto a cooperativamente construir o sistema de regras morais e operatórias necessárias à manutenção de relações permeadas pelo respeito mútuo.

Piaget apresenta que o princípio de autonomia se desenvolve com o desenvolvimento da autoconsciência. A inteligência inicialmente está relacionada em atividades motoras, centradas no próprio "eu". Fase em que a criança brinca consigo mesma, sem compartilhar com o outro, 
chamado de estado de anomia. No desenvolvimento e na complexificação das ações, o indivíduo passa a reconhecer a existência do outro, bem como a necessidade de cumprir regras de hierarquia, de autoridade. Com o controle centrado no outro, ele (o indivíduo) deixa de ser o centro em suas relações passando para uma relação unilateral, chamado de estado de heteronomia. Quando a decisão, as verdades estão centradas no outro (adulto), o indivíduo toma consciência da obrigação ou do caráter necessário de uma regra, supõe um sentimento de respeito à autoridade do outro. Na autonomia, as leis e as regras são opções que o sujeito faz na sua convivência social pela autodeterminação.

Em seu livro Pedagogia da Autonomia Paulo Freire propõe uma prática educativa "fundada na ética, no respeito à dignidade e à própria autonomia do educando" (FREIRE, 2000, p. 11).

Essa educação para a autonomia deve ser conquistada, construída a partir das decisões, das vivências, da própria liberdade. Ou seja, embora a autonomia seja um atributo humano essencial, na medida em que está vinculada à idéia de dignidade, defende-se que ninguém é espontaneamente autônomo, ela é uma conquista que deve ser realizada. E a educação deve proporcionar contextos formativos que sejam adequados aos alunos, transformando-os em autônomos. A temática da autonomia que ganhou centralidade nos pensadores e na educação moderna no Brasil, ganha em Paulo Freire um sentido sócio-político-pedagógico: autonomia é a condição sócio-histórica de um povo ou pessoa que tenha se libertado se emancipado, das opressões que restringem ou anulam sua liberdade de determinação. E conquistar a própria autonomia implica, para Freire, em libertação das estruturas opressoras. Não há libertação que se faça com homens e mulheres passivas, é necessária conscientização e intervenção no mundo. A autonomia, além da liberdade de pensar por si, além da capacidade de guiar-se por princípios que concordem com a própria razão, envolve a capacidade de realizar, o que exige um homem consciente e ativo, por isso o homem passivo é contrário ao homem autônomo.

De acordo com Paulo Freire (1983, p.24) "a reflexão crítica sobre a prática se torna uma exigência da relação Teoria/Prática sem a qual a teoria pode ir virando blá-blá-blá e a prática, ativismo". Percebe-se dentro desse contexto a importância da prática docente enquanto dimensão social da formação humana.

Segundo Paulo Freire (2000) é preciso discutir alguns saberes fundamentais á prática, devendo ser conteúdos obrigatórios à formação docente. Saberes indispensáveis na experiência formadora, assumindo como sujeito da produção do saber, e que ensinar não é transferir conhecimento, mas criar possibilidades para a sua construção. 
Para Paulo Freire $(2000$, p.58) “o respeito à autonomia e à dignidade de cada um é um imperativo ético e não um favor que podemos ou não conceder uns aos outros". Ninguém é autônomo primeiro para depois decidir. A pedagogia da autonomia deve estar no centro das experiências estimuladoras da decisão e da responsabilidade. Autonomia é construída em contextos de liberdade e de resistência sem renuncia à individualidade com desejo e empenho na formação de espaços solidário.

\section{METODOLOGIA}

\section{A Política Curricular}

No intuito de melhor compreendermos a relação entre o desenvolvimento da autonomia nos alunos e a contribuição, a partir do material do Currículo de Língua Portuguesa da Secretaria da Educação do Estado de São Paulo, apresentamos de forma sucinta, o olhar de pesquisadores sobre a política curricular proposta nas escolas públicas do Estado de São Paulo.

Toda política curricular é constituída de propostas e práticas curriculares e, como também as constitui, não é possível de forma absoluta separá-las e desconsiderar suas inter relações. Trata-se de um processo de seleção e de produção de saberes, de visões de mundo, de habilidades, de valores, de símbolos e significados, portanto, de culturas capazes de instituir formas de organizar o que é selecionado, tornando-o apto a ser ensinado (LOPES, 1996). Ao mesmo tempo, são estabelecidos princípios de distribuição aos alunos e às alunas do que foi selecionada, uma distribuição freqüentemente desigual, uma vez que considerando a individualidade do aluno, o mesmo encontra-se em níveis de abrangência de conhecimentos desiguais. Todavia, as especificidades de cada individuo devem ser acolhidas de forma singular, o que permeia um plano muito mais amplo no desenvolvimento dos princípios de distribuição do que foi selecionado, reduzindo a autonomia e a capacidade de independência, o que torna mais distante a equidade que deve reconhecer o princípio da diferença dentro da igualdade (LOPES, 1996).

Diante dessa política e dos resultados insatisfatórios da escolarização, alguns pesquisadores brasileiros têm abordado a questão em suas implicações para a política curricular no campo do currículo.

Siqueira (2000), faz uma análise de propostas curriculares implementadas por práticas políticas de governos nas duas últimas décadas do século XX no Brasil. Em seu estudo, a autora admite que, "apesar das propostas terem assumido um discurso democrático, as características de 
insucesso escolar da maioria da população pouco se alteraram" (SIQUEIRA, 2000, p.82), visto que as mudanças preconizadas e implementadas no período não afetaram profundamente as questões estruturais dos sistemas públicos de ensino, responsáveis, em proporção significativa, pelos seus altos índices de fracasso.

No entanto, segundo Siqueira (2000), nota-se que as características das políticas públicas em si, podem ser igualmente atribuídas às políticas curriculares. Seus estudos denunciam ainda que, no que tange às políticas curriculares, o fracasso escolar persiste porque tais políticas demonstram um distanciamento entre avanços teóricos e práticos, e porque apresentam sintomas da globalização das políticas educacionais. A abordagem metodológica desses estudos tem mostrado o poder das chamadas "políticas oficiais" e das relações políticas no sentido global/local sobre os currículos escolares, em especial de Língua Portuguesa.

Considerando as competências e habilidades propostas nos Parâmetros Curriculares Nacionais, "o ensino de Língua Portuguesa, atualmente, busca desenvolver no aluno seu potencial crítico, sua percepção das múltiplas possibilidades de expressão lingüística, sua capacitação como leitor efetivo das mais diversas situações representando a nossa cultura". (BRASIL, 2002, p. 55).

Segundo o Currículo Oficial da Secretaria de Educação do Estado de São Paulo (2008) a disciplina de Língua Portuguesa precisa ser um processo de aprimoramento e desenvolvimento da capacidade de agir, pensar, atuar sobre o mundo e lidar com a influência do mundo sobre cada um, bem como atribuir significados e ser percebido e significado pelos outros, apreenderem a diversidade e ser compreendido por ela, situar-se e pertencer.

[...] educação só é possível para o homem, porque este é um ser inacabado e sabe de sua incompletude, pois ela a educação implica em uma busca realizada por um sujeito, que é o próprio homem, ou seja, ele o próprio homem deve ser sujeito de sua história, e não ser objeto dela. (FREIRE, 2000. p 48)

Dessa forma, a expressão "educar para a vida" pode ganhar seu sentido mais nobre e verdadeiro na prática do ensino. Se a educação básica é para a vida, a quantidade e a qualidade do conhecimento têm de ser determinadas por sua relevância para a vida de hoje e do futuro, para além dos limites da escola. Portanto, mais do que os conteúdos isolados, as competências são guias eficazes para educar para a vida. 


\section{CONCLUSÃO}

A autonomia refere-se às múltiplas capacidades do indivíduo em se representar tanto nos espaços públicos como nos espaços privados da vida cotidiana. Ao seu modo viver os seus valores culturais; à luta pela emancipação e desalienação; à forma de ser, sentir e agir; à capacidade de potenciar atividades em diversas formas de trabalho; à resolução de conflitos; ao fortalecimento em relação às suas próprias emoções, tornando-o capaz de solidarizar com as emoções dos outros, enfim, estar associado em suas ações. Sabe-se que um dos caminhos para a concretização da autonomia é trabalhar as competências em sua sala de aula com os alunos.

A escolha não é outra senão "decidir como ser e como agir" (GIDDENS, 1997, 94), o como "ser e agir" num contexto globalizado diz respeito à escolha de comportamentos, maneiras de participação nos espaços públicos, atitudes no espaço da produção e do consumo; porém, esta escolha não é mais dirigida por regras fixas, mas sim pela flexibilidade, o que nos leva a destacar que a ação envolvida nesse processo precisa ser consciente, peça essencial para a autonomia.

Necessita-se de um desenvolvimento de políticas públicas sociais educacionais aos adolescentes, direcionadas ao desenvolvimento de competências e habilidades para a vida acadêmica. É preciso que governantes e profissionais "da educação" dialoguem a respeito de realização de projetos educacionais, que objetivem garantir oportunidades aos alunos quanto à continuidade à escolaridade, tornando-os cidadãos autônomos.

\section{REFERÊNCIAS}

BRASIL. Parâmetros Curriculares Nacionais: Ensino Médio. / Ministério da Educação, Secretaria de Educação Média e Tecnologia. - MEC; SEMTEC, 2002.

DIAS, C. L.; MONDIN, E.M.C.; MACÊDO, D. P. de S. A profissão docente em diferentes concepções teórico-pedagógicas: os enfoques tradicionalista, construtivista e sócio-construtivista. In: TREVISAN, Z; DIAS, C.L. Profissionalização: construção do conhecimento e da identidade docente. Curitiba, Paraná: CRV, 2012. p. 71-103.

FREIRE, P. Pedagogia do oprimido. 12 ed. Rio de Janeiro: Paz e Terra, 1983.

Pedagogia da Autonomia. Saberes Necessários à Prática Educativa. São Paulo: Paz e Terra, 2000.

GIDDENS, Anthony. Modernização Reflexiva: Política, Tradição e História na Ordem Social Moderna. São Paulo: UNESP, 1997.

LOPES, J. Jean Piaget. Revista Nova Escola, n. 95, fev.1996. 
MORIN, E. A cabeça bem-feita: repensar a reforma, reformar o pensamento. 18 ed. Rio de Janeiro: Bertrand Brasil, 2010.

PIAGET, J. A psicologia da criança. Rio de Janeiro: Bertrand Brasil, 1998.

. Estudos Sociológicos. Rio de Janeiro: Forense, 1973.

. O juízo moral na criança. In: PIAGET, J; INHELDER, B. Psicologia da criança. Rio de Janeiro: Forense, 1975.

SÃO PAULO (Estado) Secretaria da Educação. Proposta Curricular do Estado de São Paulo para o Ensino Fundamental Ciclo II e Ensino Médio: documentos de apresentação. São Paulo: SEE, 2008.

Currículo do Estado de São Paulo: Linguagens, Códigos e suas tecnologias - Ensino Fundamental Ciclo II e Ensino Médio Secretaria de Educação; Coordenação geral, Maria Inês Fini; coordenação de área, Alice Vieira. - São Paulo: SEE, 2010.

SIQUEIRA, E. M. Luzes e sombras: modernidade e educação pública em Mato Grosso (1870-1889). Cuiabá: INEP/COMPED/EdUFMT. 2000. 